\title{
Determining Concentrations of Factors VIII, IX and Fibrinogen in Fresh Frozen Plasma: An Alternative to Improve Treatment of Hemorrhagic Diseases in a Developing Country
}

Diallo Yacouba $\mathrm{L}^{1 *}$, Guitteye $\mathrm{H}^{2}$, Drame Boubacar $\mathrm{S}^{3}$, Toure Ousmane $\mathrm{D}^{4}$, Cissoko $\mathrm{Y}^{5}$ and Sidibe AT ${ }^{1}$

${ }^{1}$ Service de Médecine Hôpital du Mali, Mali

${ }^{2}$ Centre National de Transfusion Sanguine, Mali

${ }^{3}$ Laboratoire de biologie Hôpital du Mali, Mali

${ }^{4}$ Service santé publique Hôpital du Mali, Mali

${ }^{5}$ Service de Maladies Infectieuses CHU Point, Mali

\section{Research Article}

Volume 1 Issue 2

Received Date: October 23, 2017

Published Date: November 22, 2017

DOI: $10.23880 / \mathrm{hij}-16000109$

*Corresponding author: Yacouba Lazare DIALLO, chargé de recherche en hématologie, service de médecine hôpital du Mali, 03 BP 106 Bamako, Mali, Tel: 00223692930 15; E-mail: yldialloml@gmail.com

\section{Abstract}

Fresh frozen plasma (FFP) remains the only treatment of bleeding events in some developing countries. But access to this blood derived-product could be difficult. Determined the concentrations of coagulation factors VIII, IX and fibrinogen used in Mali. We have determined prospectively the concentrations of these factors from October 2015 to February 2016 in the FFP bags produced and distributed by the National Blood Transfusion Center (NBTC) in Mali. The assays were performed in the laboratory of medical biology in Hôpital du Mali (Bamako, Mali) using a semi automaton BioSolea4. Mean volume of 342 analyzed blood bags was $249.5 \pm 42.7 \mathrm{~mL}$ (range: 130 - 374.4). Mean concentration of factor VIII was $0.4 \pm 0.4 \mathrm{IU} / \mathrm{mL}(0.02-3.56 \mathrm{IU} / \mathrm{mL})$, of factor IX $0.3 \pm 0.2 \mathrm{IU} / \mathrm{mL}(0.05-1.5 \mathrm{IU} / \mathrm{mL}) \mathrm{and}$ of fibrinogen: $2.6 \pm 0.8 \mathrm{~g} / \mathrm{L}(0.2-4.8 \mathrm{~g} / \mathrm{L})$. As expected, concentration of factor VIII of the 0 group donors was lower than in other blood groups $(0.3 \pm 0.3$ vs $0.4 \pm 0.5 \mathrm{IU} / \mathrm{mL})(\mathrm{p}=0.009)$. Similar results were obtained with rhesus positive blood bags donors compare to those from others blood groups $(0.3 \pm 0.3$ vs $0.4 \pm 0.4 \mathrm{IU} / \mathrm{mL})(\mathrm{p}=0.001)$.

Conclusion: Concentrations of coagulation factors in the FFP bags produce by NBTC are 1.6 fold lower for factor VIII, and 2.3 fold for factor IX than in other countries. We suggest that the production and distribution of cryoprecipitate could be improved for the effective management of bleeding events in resource-limited countries with no access to specific concentrate coagulation factor.

Keywords: Fresh frozen plasma; Hemorrhagic diseases; Coagulation tests; NBTC 
Abbreviations: FFP: Fresh Frozen Plasma; NBTC: National Blood Transfusion Center; SD: Standard Deviation

\section{Introduction}

The management of inheritance or acquired bleeding diseases is a real challenge in resource-limited countries [1-3]. The recent epidemic of Ebola Virus in West Africa has highlighted this difficulty $[3,4]$. The lack of mechanism for the management of hemorrhagic diseases could explain the high lethality associated to this epidemic. Indeed, the presence of hemorrhage is considered as a pejorative prognostic factor in a patient with Ebola Virus disease [4].

In obstetric context, post-partum hemorrhage is the leading cause of maternal mortality in resource-limited countries [5] specifically in Mali, [6-9]. Despite efforts of Malian health authorities such as subvention for caesarian, maternal mortality rate is estimated to 464 deaths per 100,000 births and remains one of the highest in the world $[10,11]$.

Causes of hemorrhage are various. They may be congenital such as inheritance deficiencies in coagulation factors (ex: factor VIII, von Willebrand factor, etc.) or acquired in sepsis with intravascular coagulation, hepatic disease. Whatever the cause, management of bleeding is a life-threatening emergency. Treatment includes administration of concentrates for specific clotting factor, hemostatic drugs such as ethamsylate (which increase capillary endothelial resistance and promote platelet adhesion), antifibrinolytic drugs (tranexamic acid) and fresh frozen plasma (FFP) [12-14]. Considering, its composition, FFP appears to be an efficient alternative to manage hemorrhagic episodes in hemophilic patients or in other coagulation proteins deficiency such as fibrinogen as no specific concentrate is available. Cryoprecipitate is a concentration of FFP with a high level of concentrate clotting factors. Unfortunately this product is not available in our country. In some emerging countries such as our country, FFP is the only source of clotting factors for the management of bleeding events. But access to FFP will be increasingly difficult due to the lack of regular and secured donors and the increasing need. The goal of our study is to determine the mean concentration of factor VIII, IX and fibrinogen in FFP bags produced and distributed by the National Blood Transfusion Center (NBTC) and used in our institution (Hôpital du Mali, Bamako, Mali).

\section{Material and Methods}

\section{Study Design and Data Sources}

We conducted a prospective monocentric and observational study from October 2015 to February 2016. Plasma was prepared at the NBTC in Bamako, Mali. Plasma sample was collected after centrifugation of whole blood at $4000 \mathrm{~g}$ during 12 minutes at $200 \mathrm{C}$ using an large capacity refrigerate centrifuge KR4i device (Thermo Scientific TM). Volumes of bags were determined after separation using weighing balances (Sartorius, Germany) before freezing. To prevent damage bags, we collected a sample after homogeny 4.5 $\mathrm{mL}$ of plasma before clamping and freezing. The samples were analyzed in the laboratory of medical biology in Mali hospital (Hôpital du Mali, Bamako, Mali).

Coagulation tests were performed in a maximum of 3 hours after collection on a semi-automaton Bio Solea-4 with STA® PTT Automate 5 (Stago, France), STA® Owren Koller (Stago, France) and $0.025 \mathrm{M}$ calcium chloride solution (Stago, France). Determination of factors VIII, IX, fibrinogen concentrations were performed using STA $®$ Immunodef VIII (Stago, France), STA $®$ Immunodef IX (Stago, France), Fibri Prest $\AA$ Automate 5), respectively. Results were expressed in $\mathrm{UI} / \mathrm{mL}$ for factors VIII and IX and $\mathrm{g} / \mathrm{dL}$ for fibrinogen

\section{Statistical Analysis}

Volume was determined in $\mathrm{mL}$ in all bags. Mean volume was calculated using the summarized volume divided per number of bags. Mean concentration of coagulation factor was obtained as follows: concentration/volume of the bags. All results were expressed as mean \pm standard deviation (sd) and range between minimum and maximum values.

Comparison between groups was performed using Mann-Whitney test for continuous variables with nonGaussian distribution and Student $t$ test for Gaussian distribution and using Chi square test for categorical variables. A P value $\leq 0.05$ was considered statistically significant. All statistical analyses were performed using the SPSS 17.0.

\section{Results}

From October 2015 to February 2016, 342 bags of FFP were analyzed. Mean bag volume was $249.5 \pm 42.7$ $\mathrm{mL}$ (range: 130 - $374.4 \mathrm{~mL}$ ). All 342 bags were tested for infectious disease (HIV, Hepatitis B and C and 
Syphilis). Mean concentration of coagulation factors VIII, IX and fibrinogen, blood group ABO and rhesus, were determined in all samples.

\section{Concentration of Factor VIII in FFP}

Mean absolute value of factor VIII was $96.1 \pm 90.7$ IU (5 - 645 IU). One hundred fourteen bags had less than $50 \mathrm{IU}$ and it varied between 50 and $150 \mathrm{IU}$ in $49 \%$ of the bags. It was over $150 \mathrm{UI}$ in $17.6 \%$ of the bags (Figure 1 ). Mean concentration of factor VIII bags was $0.4 \pm 0.4$ $\mathrm{IU} / \mathrm{mL}$ (range: $0.02-3.56 \mathrm{IU} / \mathrm{mL}$ ) and $83.3 \%$ of the bags had less than $0.7 \mathrm{IU} / \mathrm{mL}$ and $05.8 \%$ had more than 1 $\mathrm{IU} / \mathrm{mL}$ (Figure 2).

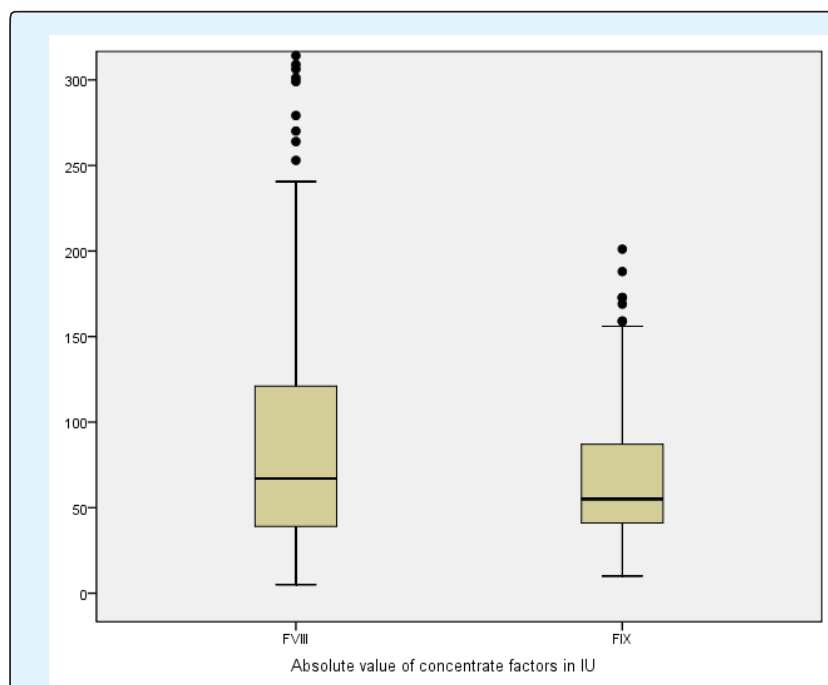

Figure 1: Samples repartition using the absolute value of coagulation factors VIII and IX.

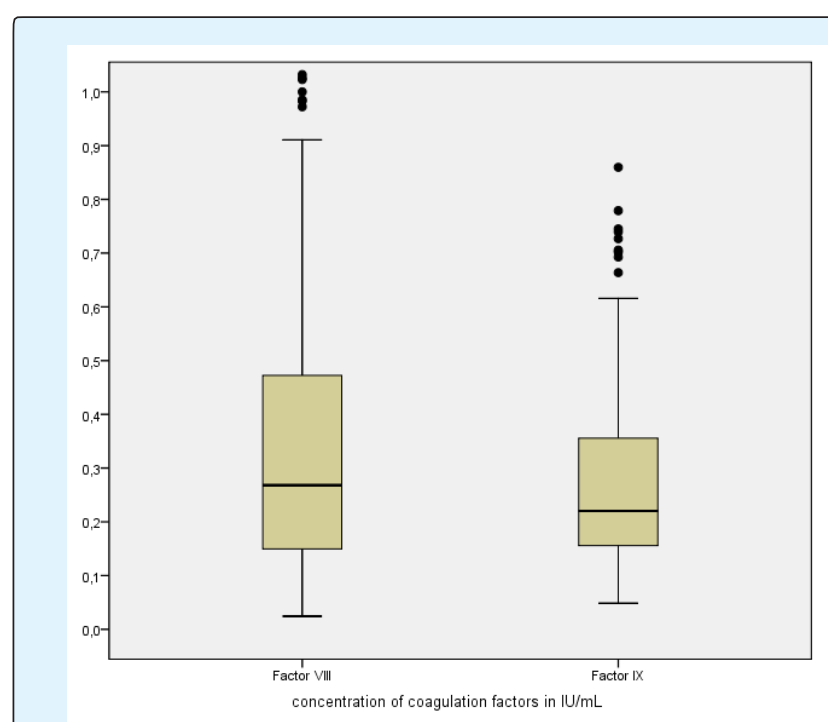

Figure 2: Sample repartition using the mean concentration of coagulation factors VIII and IX.

\section{Concentration of Factor IX in FFP}

Of the 342 bags tested, mean value of factor IX was $67.1 \pm 39.3$ IU (10 - 359 IU), 242 bags had less than 70 IU, $25.4 \%$ had varied between 70 and $120 \mathrm{IU}$, and9.6\% had less than 70 IU (Figure 1). Mean concentration of factor IX by bag was $0.3 \pm 0.2 \mathrm{IU} / \mathrm{mL}$ (range: $0.05-1.5$ $\mathrm{IU} / \mathrm{mL}$ ) and $97 \%$ of bags had less than $0.7 \mathrm{IU} / \mathrm{mL}$ (Figure 2).

\section{Concentration of Fibrinogen in FFP}

Mean concentration of fibrinogen was $2.6 \pm 0.8 \mathrm{~g} / \mathrm{L}$ (range: 0.2 - $4.7 \mathrm{~g} / \mathrm{L}$ ), $22 \%$ had less than $2 \mathrm{~g} / \mathrm{L}$ and the concentration varied between 2 and $4 \mathrm{~g} / \mathrm{L}$ in $76.8 \%$ ) of the bags. Only 4 bags (1.2\%) had more than $4 \mathrm{~g} / \mathrm{L}$.

\section{Determination of Immunological and Hematological and Infectious Profile in FFP}

Group repartition was as follows: $41.7 \%$ of the bags were of 0 group, $29.5 \%$ of B group, $22.7 \%$ of A group, and $6.1 \%$ of $\mathrm{AB}$ group. Table 1 summarizes distribution of bags according to $\mathrm{ABO}$ and rhesus group.

\begin{tabular}{|c|c|c|c|}
\hline Groups & $\begin{array}{c}\text { Nb of bag number of } \\
\text { bags (\% of total) }\end{array}$ & Rhesus & Nb of bags \\
\hline 0 & \multirow{2}{*}{$143(41.7)$} & Positive & $131(96.6)$ \\
\cline { 3 - 4 } & \multirow{2}{*}{$\mathrm{B}$} & Negative & $12(08.4)$ \\
\hline $\mathrm{A}$ & \multirow{2}{*}{$78(22.7)$} & Positive & $97(96)$ \\
\cline { 3 - 4 } & \multirow{2}{*}{$21(06.1)$} & Negative & $04(04)$ \\
\cline { 3 - 4 } & & Negative & $72(92.3)$ \\
\cline { 3 - 4 } & & Positive & $20(95.07)$ \\
\hline
\end{tabular}

Table 1: Summarizes of bags distribution by blood group (ABO-Rh).

Concentration of factor VIII of the 0 group donors was lower than in other blood groups $(0.3 \pm 0.3$ vs $0.4 \pm 0.5 \mathrm{IU} / \mathrm{mL}) \quad(\mathrm{p}=0.009)$. Similar results were obtained with rhesus positive blood bags donors compare to those from others blood groups $(0.3 \pm 0.3 \mathrm{vs}$ $0.4 \pm 0.4 \mathrm{IU} / \mathrm{mL})(\mathrm{p}=0.001)$. No difference was observed with factor IX and fibrinogen.

\section{Qualifying Tests for Infectious Diseases}

Of the 342 bags analyzed, 66 bags (19.3\%) were not qualified for distribution due to an infection risk. 48 bags $(14.3 \%)$ were contaminated by hepatitis B, 14 bags (4.1\%) by hepatitis C, 8 bags $(2.3 \%)$ by HIV, and one bag $(0.3 \%)$ by syphilis. Five cases of co-infection were also observed: 3 cases by HIV+Hepatitis B and 2 by Hepatitis B+C (Table 2). 
We did not found any correlation between HIV, hepatitis and syphilis infections and concentrations of different coagulation factors.

\begin{tabular}{|c|c|c|}
\hline \multirow{2}{*}{ Diseases } & \multicolumn{2}{|c|}{ Results number of bags (\% of total) } \\
\cline { 2 - 3 } & Negative & Positive \\
\hline Syphilis & $342(99.7)$ & $01(0.3)$ \\
\hline HIV & $335(97.7)$ & $08(2.3)$ \\
\hline Hepatitis C & $329(95.9)$ & $14(4.1)$ \\
\hline Hepatitis B & $294(85.7)$ & $48(14.3)$ \\
\hline TOTAL $^{*}$ & $276(80.7)$ & $66(19.3)$ \\
\hline
\end{tabular}

*:Co-infection HIV+Hepatitis B: 03/66 (4.5\%), Hepatitis B+C: $02(3 \%)$.

Table 2: Bags distribution according to the results of the infectious diseases tests qualifications.

\section{Discussion}

The aim of this study is to contribute to the improvement of management of patients with congenital or acquired hemorrhagic diseases in Mali. In the present study, we determined concentration of factor VIII, IX and fibrinogen in FFPs bags produced and distributed by NBTC and used in the Mali hospital (Hôpital du Mali, Bamako, Mali), before freezing. We compare FFP concentration to clotting factors reported in France and the literature. FFP is a labile blood product with numerous and varied indications in current medical practice $[12,13,15,16]$. In developing countries in Africa, FFP remains the only source of clotting factors available for the management of hemorrhagic diseases such as hemophilia and other bleeding diseases $[1,16]$.

In our study, we included 342 bags produced by NBTC of Bamako. Plasma was prepared by centrifugation using a high capacity refrigerate centrifuge. After this separation plasma samples from bags was collected before freezing and tested in our laboratory to determine the concentration in factor VIII, IX and fibrinogen. We used coagulation method to determine means concentrations of factors VIII, IX and fibrinogen using semi automaton. This method has the advantage of be easily accessible and cheaper in resource-limited countries. In this study, mean concentrations were respectively $0.4 \pm 0.4 \mathrm{IU} / \mathrm{mL}$ for factor VIII, and $0.3 \pm 0.2 \mathrm{IU} / \mathrm{mL}$ for factor IX. Our values are lower than mean concentrations of factors VIII and IX, reported in the literature $[12,17,18]$, which varies between 0.7 and $1 \mathrm{IU} / \mathrm{mL}$ for factor VIII. This difference could be due to the methods of plasma preparation. Usually in foreign countries, plasma was obtained by apheresis. In our case plasma was obtained by separation after centrifugation. The delay between whole blood collection and plasma separation could be long, which can reduce the concentration level of factors by degradation. Another hypothesis could be the mains manipulation of plasma during the separation process and the delay before freezing which could also alter the quality of samples. Mean concentration of fibrinogen in our study was $2.6 \pm 0.8 \mathrm{~g} / \mathrm{L}$ This mean concentration is comparable to mean concentrations reported in France, which varies between 2.7 and $2.8 \mathrm{~g} / \mathrm{L}$ depending on the type of plasma [17].

In France, factor VIII concentration of plasma is an indicator of validation of the preparation of the plasma and of the cold chain system and that of fibrinogen is an indicator of quality [17]. To our knowledge in Mali and in many others African countries, no validation standards and quality indicators exist. If our data are confirmed, this step should be taken into account in plasma preparation in Mali and in others developing countries that used the separation method by centrifugation.

Albanez S, et al. [19] showed the influence of age and the ABO group on the plasma concentration of coagulation factor $[19,20]$. We were not able to study this point as this parameter was not recorded in our study. By studying the role of the ABO group and rhesus together, we found that bags of the 0 group had lower mean concentrations of factor VIII than those of other groups. This finding, which is rarely discussed, could have an impact on the use of FFP in current practice. It should be confirmed in a large population before suggest any hypothesis.

Finally we have shown that $19.3 \%$ of tested bags were not qualified for distribution due to Hepatitis B (14.3\%) and C (4.1\%), HIV (2.3\%) and Syphilis infections $(0.3 \%)$. This rate of unqualified bags seems high $[21,22]$. This situation needs attention during the donors screening process. We do not investigate the reasons of this situation.

\section{Conclusion}

This study provides an overview of concentration of factor VIII, IX and fibrinogen in FFP bags produced by NBTC in Mali. Factors VIII and IX concentrations appear to be less than usual reported ones in France for instance. We suggest that production of cryoprecipitate should be carefully controlled as it is required for management of hemorrhagic events in resource-limited countries with no access to concentrate coagulation factor. We also suggest improving concentration of these factors in FFP produced in Mali. 


\section{References}

1. Maurin O, Martinaud C, Boulesteix G, Eve O, Bertani A, et al. (2012) Management of bleeding in a child with haemophilia in Africa with freeze-dried plasma. Haemophilia 18(1): 38-39.

2. Mamoudou S, Boushab BM (2016) Hemorrhagic form of dengue fever observed at the Infectious Diseases Department CHU Yalgado Ouedraogo, Burkina Faso. Pan Afr Med J 23: 168.

3. Abdullah S, Karunamoorthi K (2015) Ebola and blood transfusion: existing challenges and emerging opportunities. Eur Rev Med Pharmacol Sci 19(16): 2983-2996.

4. Barry M, Touré A, Traoré FA, Sako FB, Sylla D, et al. (2015) Clinical predictors of mortality in patients with Ebola virus disease. Clin Infect Dis 60(12): 1821-1824.

5. Neal S, Shanti M, Krishna B, Alma VC, Matthews M, et al. (2016) The causes of maternal mortality in adolescents in low and middle income countries: a systematic review of the literature. BMC Pregnancy Childbirth 16(1): 352.

6. Diallo A (2009) Epidemiological and clinical study of obstetric emergencies at the reference health center of commune $\mathrm{V}$ of Bamako District. Medicine Thesis 134(09M134).

7. Coulibaly D (2008) Epidemiological and clinical study of obstetric emergencies at the reference health center of commune IV of Bamako District. Medicine Thesis 479(08M479).

8. Diarra D (2014) Evolution of maternal mortality in the Gynecology-Obstetrics Department at Fousseyni Daou Hospital in Kayes during 5 and a half years. Medecine Thesis 92(14M92): 108.

9. Dicko G (2010) Maternal Mortality and Clinical Audit at the Reference Health Center of Commune IV of Bamako District. Medicine Thesis 183(10M183).

10. Say L, Doris Chou, Alison G, Özge T, Ann-Beth M, et al. (2014) Global causes of maternal death: a WHO systematic analysis. The Lancet Global health 2(6): 323-333.

11. Pantic M, Novak A, Marisavljevic D, Djordjevic V, Elezovic I, et al. (2000) Additional chromosome aberrations in acute promyelocytic leukemia: characteristics and prognostic influence. Medical oncology 17(4): 307-313.

12. Lauzier F, Cook D, Griffith L, Upton J, Crowther M, et al. (2007) Fresh frozen plasma transfusion in critically ill patients. Critical care medicine 35(7): 1655-1659.

13. Raban MS, Harrison MC (2015) Fresh Frozen Plasma Use in a Neonatal Unit in South Africa. J Trop Pediatr 61(4): 266-271.

14. Poon MC, Card R (2012) Hemophilia management in transfusion medicine. Transfu Apher Sci 46(3): 299-307.

15. Lu Y, Sun G, Liu X, Liu Z, Tan J, et al. (2017) Plasma Transfusion in Patients With Cirrhosis in China: A Retrospective Multicenter Cohort Study. Transfus Med Rev 31(2): 107-112.

16. Figueiredo S, Benhamou D (2016) Use of fresh frozen plasma: From the 2012 French guidelines to recent advances. Transfus Apher Sci 56(1): 20-25.

17. Benhamou D (2012) Plasma transfusion: products and indications. 2012 guidelines update. Transfu Clin Biol 19(4-5):253-262.

18. Butenas S, Parhami-Seren B, Anetta U, David NF, Kenneth GM (2010) The "normal" factor VIII concentration in plasma. Thromb Res 126(2): 119123.

19. Albanez S, Ogiwara K, Michels A, Hopman W, Grabell J, et al. (2016) Aging and ABO blood type influence von Willebrand factor and factor VIII levels through interrelated mechanisms. J Thromb Haemost 14(5): 953-963.

20. Preston AE, Barr A (1964) The Plasma Concentration of Factor VIII in the Normal Population II. The Effects of Age, Sex and Blood Group. Br J Haematol10: 238-245.

21. Batool Z, Durrani SH, Tariq S (2017) Association Of Abo And Rh Blood Group Types To Hepatitis B, Hepatitis C, Hiv And Syphilis Infection, A Five Year' Experience In Healthy Blood Donors In A Tertiary Care Hospital. J Ayub Med Coll Abbottabad 29(1): 90-92.

22. Attaullah S, Sanaullah K, Jabbar K (2012) Trend of transfusion transmitted infections frequency in blood donors: provide a road map for its prevention and control. J Transl Med 10: 20. 
Haematology International Journal 